\title{
Unusual Presentation of Mitochondrial Depletion Syndrome Related to FBXL4: A Case Report
}

\author{
Al-Buali Majed $\mathrm{J}^{*}$, Alhamad Anwar $\mathrm{R}^{2}$, Al-Obaid Jaafer $\mathrm{J}^{3}$, Al-Motawa Mossa $\mathrm{N}^{4}$, Al-Yaseen Mujtaba $\mathrm{A}^{2}$, Al-Haddad \\ Mousa Ali ${ }^{2}$ and Al-Ghadeer Ahmed $\mathrm{Y}^{2}$ \\ ${ }^{1}$ Pediatric Consultant and Consultant of Medical Genetics, King Faisal General Hospital, Al-Hassa, Saudi Arabia \\ ${ }^{2}$ Senior Registrar, Pediatrics, Maternity Children Hospital, Al-Hassa, Saudi Arabia \\ ${ }^{3}$ Consultant Neuroradiologist, King Fahad Hospital, Al-Hassa, Saudi Arabia \\ ${ }^{4}$ Pediatric Consultant and Endocrinologist, King Faisal General Hospital, Al-Hassa, Saudi Arabia
}

\begin{abstract}
Background: Mitochondrial depletion syndrome (MDS) is phenotypically heterogeneous and may affect either single or multiple organs including muscles, liver, brain, and kidneys. FBXL4-related mitochondrial depletion syndrome of encephalomyopathic type is a severe condition that begins at an early age. It is primarily linked to brain dysfunction combined with muscle weakness.
\end{abstract}

Case presentation: In the present case, a homozygous loss of function variant of FBXL4 (MIM 605654) was identified by whole exome sequencing (WES) in a three-year old Saudi girl who exhibited biochemical, and cerebral magnetic resonance imaging features consistent with mitochondrial DNA depletion syndrome 13, but had different presentations which has not been reported before.

Conclusion: MDTP13 (encephalomyopathic type) is caused by biallelic pathogenic variants in FBXL4. There is remarkable variability in genotypeto-phenotype correlation characteristic of this disease.

Keywords: FBXL4 • mitochondrial DNA • Depletion Syndrome • Encephalomyopathic Type $・$ Case Report

\section{Introduction}

Mitochondrial diseases have an estimated incidence rate of 1 in 5000 and account for a diverse range of genetically determined multisystem conditions that are characterized by a defective mitochondrial oxidative phosphorylation system [1]. One of them is mitochondrial depletion syndromes (MDS), which is an inherited autosomal recessive condition and can be detected in areas where consanguineous marriages are common and appears in various prognoses [2]. MDS can be divided into at least four clinical presentations namely; myopathic, encephalomyopathic, hepatocerebral and neurogastrointestinal. Encephalomyopathic MDS are caused by mutations in SUCLA2, SUCLG1, or RRM2B that are usually present during infancy [3].

F-Box and leucine rich repeat protein 4 (FBXL4) is a gene contains the N-terminal half of an F-box followed by 11 leucine-rich repeats which is observed in 1/13,005 chromosomes reported in the literature to date [1]. It is found in various organs including heart, kidneys, liver, lungs, pancreas, and placenta, but not in skeletal muscles, and maps to 6q16.1-q16.3 [1]. It is located within the intermembrane space in mitochondria of cell [4]. It plays a key role in the maintenance of mitochondrial DNA and homeostasis of mitochondrial bioenergetics including energy production, chemical signaling, cell growth control and proliferation and apoptosis [4]. Affected patients present at birth or in early infancy with a clinically heterogeneous group of disorders involving multiple organ systems including global developmental delay, hypotonia, persistent lactic acidosis, facial dysmorphism, congenital cataracts, and brain atrophy secondary to more than thousand nuclear genes contributing in mitochondrial function [5].

*Address for Correspondence: Dr. Al-Buali Majed Jawad, Pediatric Consultant and Consultant of Medical Genetics, King Faisal General Hospital, Al-Haasa, Saudi Arabia, E-mail: doctormajed1@gmail.com

Copyright: (c) 2020 Al-Buali MJ, et al. This is an open-access article distributed under the terms of the Creative Commons Attribution License, which permits unrestricted use, distribution, and reproduction in any medium, provided the original author and source are credited.
A clinical case is presented which shows biochemical and molecular presentation of the FBXL-4-related mitochondrial DNA depletion syndrome (encephalopathic type) in a 3 years old girl of related Arabian origin family, who was present clinically different when compared with previous cases.

\section{Case Presentation}

A three-year-old Saudi girl was born full term, caesarean section due to premature rupture of membrane and fetal distress with APGAR score 6 at 1 minute and 8 at 5 minutes, to 35 years old mother, gravida 4, para 3 with no maternal illness. The patient's birth weight was $2.5 \mathrm{Kg}$, height was $50 \mathrm{~cm}$ and head circumference was $35 \mathrm{~cm}$, which were all normal based on Saudi growth chart standard. She was admitted to the neonatal intensive care unit for 10 days due to persistent metabolic acidosis $\mathrm{P}^{\mathrm{H}}=7.294$ (7.35-7.45), $\mathrm{PCO}_{2}=20.2 \mathrm{mmHg}(35-45 \mathrm{mmHg})$, base deficit=- $15.9 \mathrm{mmol} / \mathrm{L}(-2$ to $2 \mathrm{mmol} / \mathrm{L})$, $\mathrm{HCO}_{3}=13.5 \mathrm{mmol} / \mathrm{L}(17-24 \mathrm{mmol} / \mathrm{L})$ and a high lactic acid level $6.61 \mathrm{mmol} / \mathrm{L}$ (1.1-3.5 mmol/L), to rule out sepsis patient was treated by sodium bicarbonate and antibiotic. During this period, pediatric genetic consultation was done and was advised to get basic laboratory tests done, which were normal except microcytic anemia (Tables 1 and 2).

The tandem mass spectrometry (TMS) was normal. Urine dipstick for glucose and ketones were negative, while urine for reducing substance test, amino acid and organic acid were not available. It was recommended to continue sodium bicarbonate and the following were started; biotin, ubiquinone, riboflavin, and thiamin. As a part of initial diagnostic work up at birth, ophthalmological and hearing evaluation was done, which were normal. Furthermore, echocardiography showed patent foramen ovale (PFO), and moderate patent ductus arteriosus (PDA). Brain magnetic resonance imaging with intravenous contrast at age of one month revealed atrophic changes in the form of prominent intra- and extra-axial cerebrospinal fluid spaces, and abnormal dilatation of the perivascular spaces. Periventricular abnormal signal intensity with some restriction involving the hippocampus was also observed (Figure 1). The abdominal ultrasound showed mild left hydronephrosis.

The patient was discharged after normalizing the venous blood gas by 
Table 1. Complete blood count.

\begin{tabular}{|c|c|c|}
\hline Blood cell indices & Value & Reference \\
\hline WBC & $17.9 \times 10^{3} / \mathrm{uL}$ & $\left(8.4-34 \times 10^{3} \mathrm{U} / \mathrm{L}\right)$ \\
\hline Hemoglobin & $10.7 \mathrm{~g} / \mathrm{dl}$ & $(14.5 \mathrm{~g} / \mathrm{dl})$ \\
\hline Mean corpuscle volume & $74.8 \mathrm{ft}$ & $(95 \mathrm{ft})$ \\
\hline Platelets & $353 \times 10^{3} \mathrm{uL}$ & $\left(192 \times 10^{3} \mathrm{U} / \mathrm{L}\right)$ \\
\hline
\end{tabular}

Table 2. Biochemistry including glucose, electrolyte, renal, liver and lipid profile.

\begin{tabular}{|c|c|c|}
\hline Serum Biochemistry & Value & Reference \\
\hline Glucose & $53 \mathrm{mg} / \mathrm{dl}$ & $40-63 \mathrm{mg} / \mathrm{dl}$ \\
\hline Sodium & $140 \mathrm{mmol} / \mathrm{L}$ & $130-145 \mathrm{mmol} / \mathrm{L}$ \\
\hline Potassium & $4.23 \mathrm{mmol} / \mathrm{L}$ & $3.7-5.9 \mathrm{mmol} / \mathrm{L}$ \\
\hline Chloride & $97.6 \mathrm{mmol} / \mathrm{L}$ & $98-115 \mathrm{mmol} / \mathrm{L}$ \\
\hline Magnesium & $0.81 \mathrm{mmol} / \mathrm{L}$ & $0.63-1.05 \mathrm{mmol} / \mathrm{L}$ \\
\hline Calcium & $2.35 \mathrm{mmol} / \mathrm{L}$ & $1.9-2.6 \mathrm{mmol} / \mathrm{L}$ \\
\hline Aspartate aminotransferase & $41.9 \mathrm{U} / \mathrm{L}$ & $47-150 \mathrm{U} / \mathrm{L}$ \\
\hline Alanine aminotransferase & $13.8 \mathrm{U} / \mathrm{L}$ & $13-45 \mathrm{U} / \mathrm{L}$ \\
\hline Total bilirubin & $6.17 \mu \mathrm{mol} / \mathrm{L}$ & $(<34 \mu \mathrm{mol} / \mathrm{L}$ \\
\hline Direct bilirubin & $0.553 \mu \mathrm{mol} / \mathrm{L}$ & $(<10 \mu \mathrm{mol} / \mathrm{L}$ \\
\hline Blood urine nitrogen & $2.2 \mathrm{mmol} / \mathrm{L}$ & $0.7-6.7 \mathrm{mmol} / \mathrm{L}$ \\
\hline Creatinine & $54 \mu \mathrm{mol} / \mathrm{L}$ & $27-88 \mu \mathrm{mo} / \mathrm{L}$ \\
\hline Cholesterol & $114 \mathrm{U} / \mathrm{L}$ & $20-200 \mathrm{U} / \mathrm{L}$ \\
\hline Triglyceride & $145 \mathrm{mg} / \mathrm{dl}$ & $30-165 \mathrm{mg} / \mathrm{dl}$ \\
\hline Low density lipoprotein & $313 \mathrm{U} / \mathrm{L}$ & $180-430 \mathrm{U} / \mathrm{L}$ \\
\hline High density lipoprotein & $58 \mathrm{mg} / \mathrm{dl}$ & $34.6+6.55 \mathrm{mg} / \mathrm{dl}$ \\
\hline Ammonia & 124 then $43 \mu \mathrm{mol} / \mathrm{L}$ & 64-107 $\mu \mathrm{mol} / \mathrm{L}$ \\
\hline Lactate dehydrogenase & $313 \mathrm{U} / \mathrm{L}$ & $180-430 \mathrm{U} / \mathrm{L}$ \\
\hline
\end{tabular}

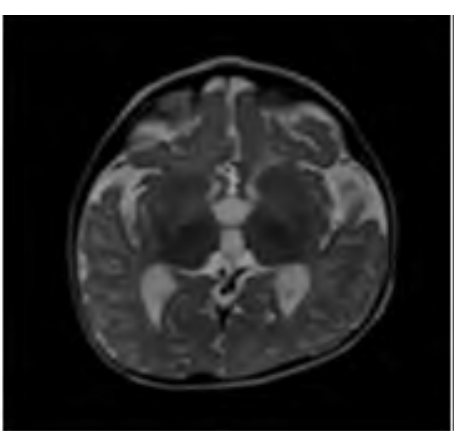

A

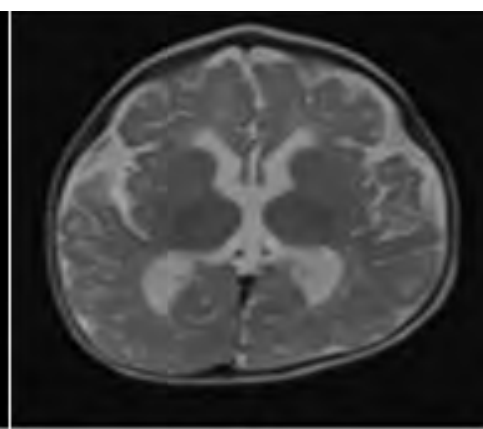

B

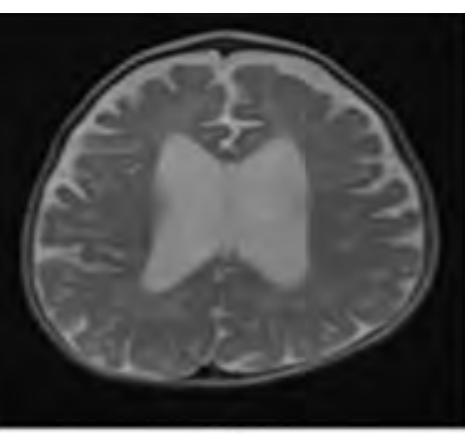

C

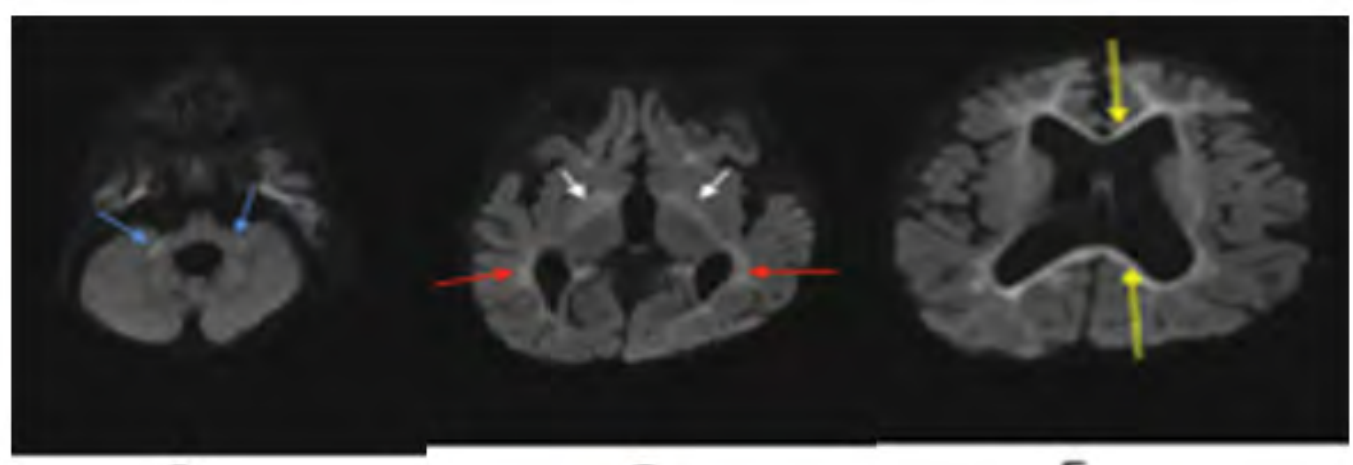

D

E

F

Figure 1. A 13-months-old baby girl. (A-C) axial T2 weighted images show brain atrophy and extensive T2 hyperintensity in globi pallidi, periventricular and deep cerebral white matter. (D-F) axial diffusion weighted images show reduced diffusion (hyperintensity) in middle cerebellar peduncles (blue arrows), globi pallidi (white arrow), corpus callosum (yellow arrows), periventricular and deep cerebral white matter (red arrows).

sodium bicarbonate and follow up was done with pediatric genetic consultant for further work up. At the age of one year, a generalized seizure disorder was developed and carbamazepine was started by neurology consultant, which was discontinued after 2 years of controlled convulsion and obtaining normal electroencephalograph (EEG).
The rate of admission to the hospital was 1-2 times per year due to metabolic crisis secondary to illness. The patient is the fifth child of related parents who were second-degree cousins (Figure 2). No family history of any neurological, metabolic, or developmental abnormalities was present.

During regular follow up physical examination revealed failure to thrive 

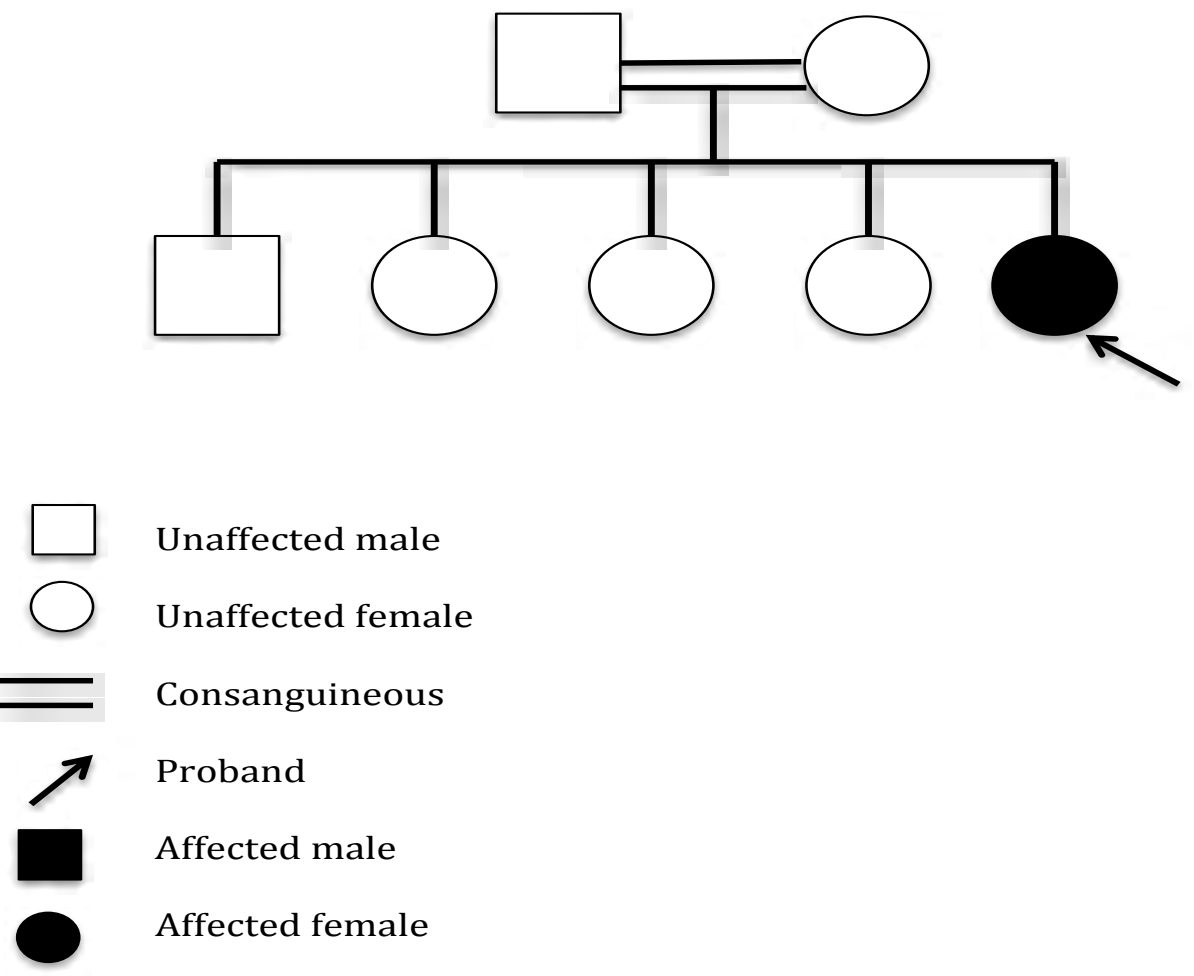

Unaffected male

Unaffected female

Consanguineous

Proband

Affected male

Affected female

Figure 2. Family pedigree of a 3-year-old girl.

\section{lactic acid follow up}

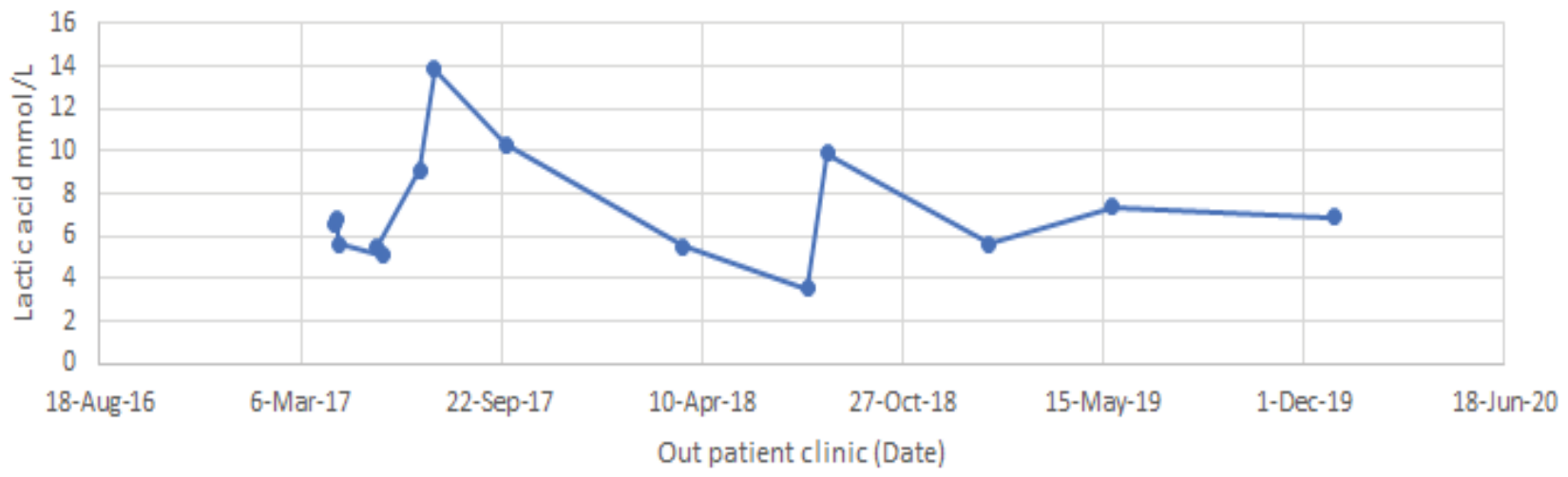

Figure 3. Trend of lactic acid over time.

Table 3. Comparison of our case manifestations to those of the three other patients reported with the same FBXL4 genotype.

\begin{tabular}{|c|c|c|c|c|}
\hline Variables & Our case & $\begin{array}{l}\text { Ballout et al. } \\
\qquad(2019)\end{array}$ & Bonnen et al. (2013) (S2) & $\begin{array}{l}\text { Huemer et al. (2015) } \\
\text { (Patient 13) }\end{array}$ \\
\hline Sex & Female & Female & Male & Male \\
\hline Age of symptom onset & At birth & 3 months & Before 1 month & At birth \\
\hline Age at presentation & 1 day & $\begin{array}{c}9 \text { months (severe anemia, mild } \\
\text { leukopenia) }\end{array}$ & 1 month & 1 day \\
\hline Birth weight (kg) & 2.5 & 2.4 & 2.3 & Unknown \\
\hline Hypotonia & Severe & Severe & Severe & Severe \\
\hline Cataracts & Absent & Absent & Present, with optic atrophy & Absent \\
\hline Cardiac anomalies & Absent & None & Cardiomyopathy & Cardiomyopathy \\
\hline Brain MRI findings & $\begin{array}{l}\text { Brain atrophy in globi pallidi, callosum, } \\
\text { periventricular, deep cerebral white matter } \\
\text { and middle cerebellar peduncles }\end{array}$ & $\begin{array}{l}\text { Bilateral temporal and frontal } \\
\text { atrophy with non-hydrocephalus } \\
\text { ventriculomegaly. }\end{array}$ & $\begin{array}{c}\text { Prominence of the Cisterna Magna, with } \\
\text { an abnormal appearance of the dorsal } \\
\text { brainstem and posterior limb of the internal } \\
\text { capsule. }\end{array}$ & Cerebellar hypoplasia \\
\hline Lactic acid levels (mmol/L) & 6.61 & 3.5 & 18 & 18 \\
\hline Ammonia levels & Non-elevated & Non-elevated & Non-elevated & Unknown \\
\hline Age at death & 3 years and still on follow up & $\begin{array}{l}\text { She was still alive at the age of } 2 \\
\text { years and } 8 \text { months, after which } \\
\text { she was lost to follow-up. }\end{array}$ & 4 months & Lost to follow-up \\
\hline
\end{tabular}


(weight $=10 \mathrm{~kg}$, height $=85 \mathrm{~cm}$, and head circumference was $45 \mathrm{~cm}$ at 3 years old, which were all below $3^{\text {rd }}$ percentile according to Saudi growth chart), mild dysmorphism in the form of a triangular face, redundant skin, low set ears, and small chin. Also, there was kyphosis, generalized hypotonia, hyperreflexia, bilateral pes cavus, psychomotor delay and diffused muscle wasting. Also, she had profound motor and mental developmental delays that manifested as swallowing dysfunction, poor head control, inability to sit or roll over, and impaired speech development (developmental age was 3-4 months) while her age was 3 years. PDA and PFO were closed by itself after one year of birth, and hydronephrosis at age of 10 months was resolved without intervention.

The patient was referred to a tertiary hospital for simple whole exome sequencing at age of 16 months as the author's hospital did not offer this service. A homozygous loss of function variant of FBXL4 (FBXL4:NM_0121 60:exone6:C.1303C>T:p.R435X) was identified and was reported previously as a disease-causing mutation in the Human Gene Mutation Database (HGMD), which is collated with all published gene lesions responsible for human inherited disease. This mutation is considered as pathogenic for mitochondrial-complex 1-deficiency mitochondrial deletion syndrome 13 (encephalomyopathy type). There was also a heterozygous variant of NDUFS1 (NDUFS1: NM_001199982: exon 12: c.1306C>G: p. L436V), whose role was unclear. After that, the family was counseled for sending sample from parents and siblings to confirm segregation and pre-implantation gestation diagnosis. She continued to follow up in outpatient department for controlling metabolic acidosis by sodium bicarbonate, where the degree of involvement of different systems were assessed comprehensively and symptomatic management was provided (Figure 3).

\section{Discussion}

Mitochondrial DNA depletion Syndrome is a group of genetic disorders caused by defects in multiple genes in mitochondrial DNA(mtDNA) maintenance. Among those is FBXL4 mutation. To the best of author's knowledge, this patient represented the $95^{\text {th }}$ case of Mitochondrial DNA Depletion Syndrome 13 (MTDPS13) related to pathogenic mutation in FBXL4 in a 3 years old Saudi girl worldwide [6]. Majority of this genotype were presented at birth with lactic acidosis, severe hypotonia, encephalopathy, epilepsy, kyphosis/scoliosis, cardiomyopathy, poor neurodevelopmental outcome, growth retardation, mildly craniofacial dysmorphic features, and mortality during infancy [7]. Whole exome sequencing showed this case had MTDPS13 with an underlying FBXL4 mutation that had been reported in related individuals (c.1303C > T).

This article provides a comparison of the presented case with all FBXL4deficient cases, which have been reported in the previous literature to act as a future mutation reference table for updates and association studies [6].

The present case was similar in presentation with Bonnen et al. but cardiomyopathy, signs, sensory-neuronal hearing impairment, cataract and optic atrophy were preserved [1]. On the other hand, expected survival time was extended more than infancy and had lower complications (anemia, leukopenia and hypoalbuminemia) like the case reported by Ballout et al. (Table 3) [6]. This emphasizes the remarkable variability in genotype-tophenotype correlation characteristic of this disease. As MTDPS13 related to FBXL4 (MTDPS13; OMIM \# 615471) is autosomal recessive, stress is laid on the importance of offering families a prompt genetic counseling and preimplantation genetic diagnosis (PGD) [4].

\section{Conclusion}

Hence, MDTP13 (encephalomyopathic type) is caused by biallelic pathogenic variants in FBXL4. Moreover, this case had various presentations clinically and is expected a survival. This should be considered as one of the differential diagnoses, especially by pediatric neurologists and geneticists for hypotonia and lactic acidosis in Saudi neonates, as its management involves a multidisciplinary team, including different specialists. However, more studies are needed to be conducted to better understand the heterogeneity of population phenotype and outcome of same genotype.

\section{Conflict of Interest}

The authors declare there is no conflict of interest.

\section{Funding}

None.

\section{Consent of Publication}

Consent for publication was obtained from the parents of the patient.

\section{References}

1. Bonnen, Penelope E, John W Yarham, Arnaud Besse and Ping Wu, et al. "Mutations in FBXL4 Cause Mitochondrial Encephalopathy and a Disorder of Mitochondrial DNA Maintenance". Am J Hum Genet 93(2013): 471-481.

2. El-Hattab, Ayman W and Fernando Scaglia. "Mitochondrial DNA Depletion Syndromes: Review and Updates of Genetic Basis, Manifestations, and Therapeutic Options". Neurotherapeutics 10(2013):186-198.

3. Barøy, Tuva, Christeen Ramane J Pedurupillay, Yngve T Bliksrud and Magnhild Rasmussen, et al. "A Novel Mutation in FBXL4 in a Norwegian Child with Encephalomyopathic Mitochondrial DNA Depletion Syndrome 13". Eur J Med Genet 59(2016): 342-346

4. https://www.omim.org/entry/605654

5. https://ghr.nlm.nih.gov/gene/FBXL4

6. Ballout, Rami A, Chadi Al Alam, Penelope E Bonnen and Martina Huemer, et al. "FBXL4-Related Mitochondrial DNA Depletion Syndrome 13 (MTDPS13): A Case Report with a Comprehensive Mutation Review". Frontiers Genet 10(2019): 39.

7. https://ghr.nlm.nih.gov/condition/fbx/4-related- encephalomyopathic-mitochondrialdna-depletion-syndrome\#resources

How to cite this article: Al-Buali Majed J, Alhamad Anwar R, Al-obaid Jaafer J and Al-Motawa Mossa N, et al. "Unusual Presentation of Mitochondrial Depletion Syndrome Related to FBXL4: A Case Report." J Mol Genet Med 14 (2020): 456 doi: 10.37421/jmgm.2020.14.456 